\title{
Digital Citizenship and Distance Education
}

\author{
Dr. Lesley S. J. FARMER \\ Professor of Library Media \\ California State University Long Beach \\ 1250 Bellflower Blvd., Long Beach, CA 90840 USA \\ Telephone: 1-562-985-4534, Fax: 1-562-985-4509 \\ E-mail: Lesley.Farmer@csulb.edu
}

\begin{abstract}
This chapter describes the role of digital citizenship, particularly as it relates to school librarianship in online learning environments. It discusses the need for digital citizenship, its curriculum and standards, its place in school librarianship program preparation, distance education issues, learning resources, and implementation for the school community. Emerging issues are also noted.
\end{abstract}

\section{Introduction}

The world is changing faster than ever because of socio-economic factors, which have been significantly impacted by technology. As the world seems to grow smaller, due to increased communication and population transience, the global scene reflects a more interactive mode relative to information. Economic and social activities rely on information and communication technologies. Therefore, the need for critical use of information is more important than ever. In a digital world where the amount of information doubles every two years, individuals need to evaluate resources carefully and determine how to use relevant information to solve problems and make wise decisions. It is no longer principally an issue of getting information: it's getting the right information at the right time to do things right and to do the right things. Teaching about information and technology is not enough. It is imperative to teach learners how to be responsible and ethical users of them. They need to be digital citizens.

To this end, librarians are well positioned to provide this instruction, independently and in collaboration with the rest of the educational community. As resource managers, librarians know how to use information effectively and ethically. In particular, librarians in school settings know the school curricula so they can collaboratively incorporate digital citizenship into learning activities. However, digital citizenship is a recent concept so that pre-service and in-service school librarians will need training in order to implement this concept effectively into school settings.

This paper therefore discusses digital citizenship, its curriculum in K-20 education, and school librarian preparation with a focus on distance education. 


\section{Background}

Digital citizenship instruction needs to be contextualized in terms of societal realities, the role of school librarians, and instruction.

\section{The Information Society}

This information society impacts existing institutions and cultures. The speed and globalization of information leads to constant change, which can be hard to digest and manage. The majority of jobs now involve technology and other related new skills, so that the idea of a "terminal" degree or a static skill set is becoming an outdated paradigm. Rather, adults often need to "retool" themselves throughout their work lives. Particularly for adults who are largely digital immigrants, this new world of information, especially in electronic form, can be puzzling and overwhelming. Do they have enough background information to understand and use the new information? What then do today's learners need to know and be able to do?

- Be information literate: access, evaluate, use

- Be lifelong learners: pursue interests, read, generate knowledge

- Be socially responsible: uphold democracy, be ethical, cooperate. These skills, knowledge and dispositions lead to digital citizenship.

\section{Technology Use}

In 2010400 million people had Facebook accounts, 126 million blogs exist, 50 million tweets are created daily, and 91 percent of mobile web users access social networking sites. Additionally, 44 percent of online videos viewed are done at the workplace (Kennedy, 2010).

What are people doing online? learning social rules, designing profiles, exploring identity, writing blogs, writing software codes, sharing producing music, discussing interests, producing social documents, doing social and political activism, keeping friends, assessing risk. What else are they doing? seeking validation, competing for popularity, venting, showing off, embarrassing oneself, damaging reputations, getting even, threatening, harassing. They also may be victims of online cons and abuse.

In short, individuals build and impact their digital reputation every time they go online, especially when doing social networking. Particularly because the workplace can monitor online activity, individuals need to be aware of their technology behavior at all times. While protective actions can be put in place such as Internet filtering software and spyware, people need education more than protection. Indeed, today people need to develop their digital footprint and online reputation.

\section{Digital Citizenship}

Digital citizenship may be defined as the ability to use technology safely, responsibly, critically, productively, and civically. Two national sets of recent standards reinforce the need for digital citizenship, informing the standards committee, the teacher librarian community, and the rest of the educational community. The 2007 International Society for Technology in Education (ISTE) national education technology standards for students and 2008 standards for teachers address these same issues of technological responsibility. Students must exhibit digital 
citizenship, and teachers are supposed to "promote and model digital citizenship and responsibility." Likewise the Standards for the $21^{\text {st }}$ Century Learner developed in 2007 by the American Association of School Librarians, asserts that "ethical behavior in the use of information must be taught" (p. 2). Several of the United States 2010 national Common Core state standards reiterate the need for digital citizenship across the curriculum: most directly being to use technology and digital media strategically and capably, but also supported by respond to the varying demands of audience, task, purpose, and discipline; comprehending and critiquing; valuing evidence; and understanding other perspectives and cultures.

The overarching goal is effective and responsible personal and social engagement with digital resources for learners. While some of the motive is protection and safety, such as the federal S 1492 Broadband Data Improvement Act, which mandates that schools receiving e-rate discounts must teach students about appropriate online behavior include cyberbullying response, a more positive spin is the need for learners to learn coping skills and demonstrate that they can contribute meaningful knowledge to the digital society.

\section{School Librarians' Role}

Who is best positioned to teach all students about how to access and process information in myriad forms within the framework of academic content standards? School librarians. They are truly resource persons, providing value-added physical and intellectual access to information and ideas. Not only do school librarians know how information is created, disseminated, organized and used across the curriculum and beyond, but as trained classroom teachers they know how to teach the entire school community how to be fluent and responsible users of these resources. Civically, informed citizens can make better decisions and act on them. Extended to the cyber environment, digital citizenship necessitates gleaning electronic information, and participating actively in cyberspace to act wisely on that information for societal and personal improvement. California's 2011 model school library standards for students delineate what students should know and be able to do at each grade level or grade span relative to information literacy skills into all areas of learning. Within this framework, the responsible use of digital resources is incorporated.

\section{Training School Librarians}

With their knowledge about information processes, school librarians should spearhead digital citizenship instruction. However, they need training themselves first if they are to address this issue effectively.

\section{Need for Training}

While technology may sometimes feel ubiquitous in today's society, its use is not ubiquitous in education. Even with well-maintained labs and a solid collection of digital resources, learners will not profit from technology-enhanced activities if educators do not provide such learning opportunities. For the most part, the chief reason that digital citizenship is not taught beyond the basics of avoiding inappropriate websites and plagiarism and is lack of knowledge on the part of the educators themselves, including school librarians. Most of them are digital immigrants, and have not experienced a technology-rich academic setting themselves. 
Many school librarians use technology on a personal basis, such as communication, but have not had formal training in technology-integrated instructional design. Therefore, many do not feel comfortable in teaching digital citizenship in the library or online. On the other hand, school librarians have life experiences and a developed moral sense that they can leverage when incorporating digital citizenship. School librarians need to model digital citizenship in its infrastructure and actions: providing equitable access to digital information, making provisions to ensure that the educational community is digitally safe, having a plan to secure and protect educational data in case of crime or disaster, maintaining privacy and confidentiality of individual records, creating and enforcing policies that product the digital rights of everyone, and training staff to keep them current in digital citizenship education themselves.

\section{School Librarian Preparation Programs}

School librarian programs prepare candidates to demonstrate competence in service and leadership as teacher librarians serving Preschool, K-12, and Adult students. These programs address the philosophy, principles and ethics of the field. Pre-service school librarians (candidates) are prepared in the areas of teaching and learning, information access and delivery, collaboration, advocacy, and program leadership in order to ensure that students as well as staff are effective users of ideas and information.

To ensure that programs prepare pre-service candidates to meet these challenging expectations, the California Commission on Teacher Credentialing has developed rigorous standards based on research findings, national and state professional documents, expert opinion, and accepted best practices in the field. The 2011 revised standards include appropriate instructional content and pedagogy designed to introduce candidates to effective school library programs that include distance learning, and provide opportunities for candidates to demonstrate school librarian skills in teaching information and digital literacy in face-to-face and online environments. Three of the four standards for this authorization deal specifically with digital citizenship (p. 10).

Standard 11: Digital Literacy in the Classroom. The program provides opportunities for candidates to model effective use of technology tools and resources. Candidates model and facilitate digital citizenship: the safe, responsible (ethical/legal), critical, creative and pro-active use of technology. Candidates explain how formats and communication channels impact information.

Standard 12: Pedagogy of Information and Digital Literacy in Multiple Learning Environments. The program provides opportunities for candidates to assess student interactions with information; apply appropriate interventions to enable students to process information purposefully, ethically and effectively; design curriculum and instruction that teaches students how to effectively and responsibly utilize information.

Standard 13: Field Experience. Fieldwork includes candidate development of a hybrid curriculum unit, which includes a teaching experience in an on-line learning environment. Candidates have opportunities to instruct both K-12 students and school community adult members in effective use of information. 


\section{Distance Education}

Increasingly, school librarians are trained online or in hybrid programs. In California, for instance, only one preparation program still offers substantial face-to-face instruction. Distance education enables institutions to reach a broader geographic area and serve previously underserved populations. Distance education also eliminates the need for classroom space, although that same amount of funding might need to be reallocated for technology such as hardware, software, and Internet connectivity. On their part, pre-service and in-service school librarians often like the convenience of distance education in terms of transportation and timing. However, some school librarians feel isolated or technologically inadequate.

The following list explains andragogical (i.e., adult learning) factors that instructional designers need to apply to distance education learning about digital citizenship (Knowles, Swanson, \& Holton, 2011).

- Experience. Adults have extensive and diverse experiences, which influence how they engage with technology. Help school librarian learners identify what they already know and then build on that knowledge. Realize that adult learners might have little digital information experience so explicit instruction on technological use is necessary.

- Timing. Adults have many demands for their time, so they need to fit learning within the framework of the rest of their lives. E-learning activities have the benefit of typically being able to adjust to existing schedule demands, offering options for selfpacing.

- Practicality. Hands-on, concrete technology-rich learning activities that address needed information about digital citizenship work well with school librarian learners, especially if they can apply that information to their practice immediately.

- Socialization. Provide opportunities for school librarian learners to share information about digital citizenship using digital citizenship skills. By offering these outlets, learners are more satisfied with the distance education experience and learn more.

- Motivation. Adults are motivated internally: by job needs, personal desire, and selfesteem. Whenever possible, digital citizenship learning activities should be developed in response to school librarian interests and needs. For instance, school librarians may want to learn digital citizenship skills in order to connect with their extended families or to solve student copyright problems, so they would be more likely to try using technology than otherwise.

- Need to know. Adults need to know what they are going to learn and why they are learning it before they commit to the learning. An information need determined by school librarian learners offers an ideal opportunity for instructional designers to leverage the opportunity to design and introduce distance learning activities that incorporate digital citizenship.

- Readiness. Adults learn when they see a need to learn in order to cope with their lives or improve them. As with motivation, readiness should dictate opportunities for incorporating digital citizenship. Instructors should corporate methods of dealing with change since that aspect of e-learning may be unexpected and uncomfortable.

It should be noted that the choice of technologies and implementation of digital citizenship, both in terms of content and processes need to be addressed in light of the entire 
instructional design. Technology-based choices apply at each step in designing digital citizenship instruction, as shown here (Maloy, et al, 2011).

- Assess needs: online survey, video capture of behavior, analysis of website "hits"

- Identify learners: online solicitations, RSS feed subscriptions, organizational lists

- Identify outcomes: technology standards, digital citizenship standards

- Identify indicators: technology rubrics, technology products, electronic Delphi method (i.e., getting experts to come to consensus on key points)

- Identify prerequisite skills: web-based assessment, performance observation, content analysis of sample work

- Identify curriculum: online training documents, electronic journal articles, iUniversity podcasts

- Identify the instructional format:

- resources (Internet, DVDs, e-books)

- instructor (school librarian, classroom teacher, technology specialist, remote-site expert)

- methods (web tutorial, hands-on instruction, video presentation)

- timeframe (self-paced, real-time, just-in-time)

- location (library, computer lab, classroom, home)

- grouping (individual, online group, work unit)

- individualization (programmed instruction, choice of technology, coaching)

- affective domain (wiki, threaded discussion, virtual chat)

- Contextualize instruction: web page within work website, professional development database, digital images of applications

- Implement the plan: courseware, web page development, video conferencing

- Assess the plan: online peer review, rubrics, videotape, online survey

- Manage the learning environment:

- Use network supervision software to monitor learner use of computers

- Create technology-enhanced learning stations

- Produce a class Web site that includes assignments, exemplars, and resources

- Create a wiki for learners to share information

Even with these suggestions, technology is sometimes added on top of existing instruction, like icing on the cake, rather than transforming instructional design. Some of the changed elements include: the locus of control from teacher to learner, just-in-time learning, emphasis on resource-rich inquiry, and heightened interaction.

\section{In-Service Professional Development}

Because digital citizenship is a relatively new concept, most practitioner school librarians will need training on this concept. However, professional development targeted to school librarians is uneven. School districts are likely to have more generic training, although digital citizenship would be a good cross-curricular topic. Even though school librarians actively seek opportunities to collaborate with others, collaborative professional development for school librarians may be infrequent or difficult to do because only one or two school librarians serve at any school site. For that reason, distance education is not only more convenient and can address 
specific concepts, but the online environment can provide a venue for networking and community building.

Several distance education venues can be used to train school librarians in digital citizenship. Blogs, wikis, and social bookmarking tools enable school librarians to share documents asynchronously. Real-time online chat (e.g., http://www.tappedin.org) offers school librarians an opportunity to participate in guided group discussion; the online session is recorded and archived, and virtual offices store group documents. Webinars are a popular venue for school librarians to participate in PD because experts can share their insights anywhere, anytime for one-time or a series of archivable short sessions; documents can be shared online, and participants can interact with the presenter and peers via chat or microphone. A more advanced technology is video conferencing, which adds a video component. Virtual reality environments such as Second Life enable school librarians to interact using avatar representations; as with online chat, the sessions can be recorded, but the hardware and training can be challenging.

\section{Learning 2.0}

One specific example of professional development that enables school librarians to participate on several levels is the Learning 2.0 initiative of the California School Library Association (CSLA), which consists of self-paced web-based tutorials on web 2.0 tools and other learning technologies. For the past four years, CSLA members have created and offered these interactive modules on a volunteer basis. Starting with a set of modules based on the work of public and special librarians focusing on school librarianship, CSLA members have developed subsequent sets of modules, including one set on digital citizenship (http://ecitizenship.csla.net/). These modules link to a research-based member-created wiki on K12 digital citizenship (http://k12digitalcitizenship.wikispaces.com), which includes resources, lesson plans, and presentations. A CSLA team also serves as learning cheerleaders, encouraging and supporting the PD participants. These modules are free to anyone worldwide and have been used by individual librarians, groups, and pre-service preparation programs.

For example, the author as a library educator used both the original CSLA and their assistive technology PD modules for an online course on emerging technologies for school librarians. Alongside other readings, the course instructor assigned a module each week, and had students blog their experiences; they also had to comment on a peer's blog entry each week. They were graded on their quality of their reflections but not on their expertise. The content matter also informed the students' efforts to create a technology plan that addressed the needs of students with special needs, which was graded in terms of the feasibility, quality, and thoroughness of their plan. Students remarked to the instructor that they enjoyed the PD, and a couple stated that they appreciated using new tools and being able to explore the sites as they wished.

To investigate possible significant differences in using this like of online modular curriculum for pre- and in-service school librarians, the following conditional variables were analyzed.

- Pre- vs. in-service status. Almost all CSLA members were practitioners, although a few are students (who generally are working in school libraries while pursuing their degrees). Most of the Clarion students were pre-service librarians. The main difference, regardless of the organizational context in which they participated in CLSA's PD was 
the type of reflections expressed. Participants tended to link their online experiences to their workplace.

- Self-paced vs. time-specific. The timeframe for individual module completion and overall completion was largely determined by the module deliverer. The course tended to be more time-specific, which facilitated student sharing of experiences.

- Integrated vs. stand-alone status. All participants linked the PD to their personal lives an workspace. The course students also linked the modules to the rest of their degree program. Nevertheless, participants who experienced the PD as a stand-alone module tended to explore the modules in a more relaxed manner. While on one hand, course students were able to leverage the modules to inform the rest of their coursework, they sometimes felt "pulled" between the modules and the other readings.

- External vs. internal incentives. The incentive for ongoing participation and timely completion was higher staked in the course as well. In that respect, course effort was more externally motivated than for CSLA members, and more stressful. However, the benefits were also more apparent for the course enrollees.

- Social support. Both groups were encouraged by their peers, be they organizational or curricular based. Sometimes the CSLA cheerleaders knew the participants personally, which seemed to increate the impact of the encouragement. Likewise, when students knew each other from other courses, their connections were more specific and personal. The instructor provided an academic type of support, which was not part of the CSLA experience, but the latter did provide for some mentoring potential.

Findings inform the development and deployment of such structured PDs for teaching digital citizenship. In the final analysis, the CSLA PD was effective for both practitioners and pre-service participants. The more structured course required more responsibility and accountability on the part of the students, which was both more stressful but also more impactful. Both approaches were appropriate for the stages of the participants, and fostered communities of practice. The one advantage of the CSLA member approach was the repetition of the PD offering and incentives, the veteran cheerleaders, and a growing body of practitioners who served to motivate new participants to join and contribute.

\section{Recommendations for K12 Implementation}

Education has as its goals, among others, to prepare students to become effective lifelong learners, responsible citizens, and positive contributors to society. Digital citizenship crosses curricular lines. On a systemic level, the entire learning community can examine digital citizenship competency alongside subject matter standards in an effort to develop an interdependent matrix of learning activities that can insure learner competent. Just as each training session builds on the prior knowledge set, so to can digital citizenship skills build upon prior experience that is contextualized to optimize meaningful engagement.

Using this approach, classes can also focus on one digital citizenship skill, such as working cooperatively toward a goal, which can be implemented in a physical education or music class as well as in a science class. Similarly, if students are comfortable evaluating print resources, they can concentrate on evaluating web-based resources for the moment. Having a school-wide scope and sequence across curricular areas provides a venue for meeting specific digital citizenship standards and linking them to the overall intellectual framework. 


\section{K-12 Digital Citizenship Curriculum}

The overarching goal is effective and responsible personal and social engagement with digital resources for K12 students. While some of the motive is protection and safety, which has resulted in required filtering software and acceptable use policies, a more positive spin is the need for K12 students to learn coping skills and demonstrate that they can contribute meaningful knowledge to the digital society.

Taking a developmental approach, the 2010 California model library standards translate responsible digital literacy into concrete actions, as exemplified in these sample outcomes. National common core standards can also be incorporated into the lessons. Here are sample grade-level standards that can be applied to digital citizenship instruction.

Grade Two:

- Arts: 3.1 Explain how artists use their work to share experiences or communicate ideas.

- Library: Use computer software graphic elements and navigational tools (e.g., buttons, icons, fields). Identify the purpose of an advertisement including Internet pop-ups.

\section{Grade Five:}

- English: 2.5 Distinguish facts, supported inferences, and opinions in text.

- Library: Compare and contrast information obtained from subscription databases and from open-ended search engines on the Internet. Use basic safety procedures when emailing, texting, chatting, etc.

Grades Seven and Eight:

- Science: 7b Use a variety of print and electronic resources (including the World Wide Web) to collect information as evidence as part of a research project.

- Library: Understand and communicate the ethical use of intellectual property. Use a variety of media to impart information, share opinions, and/or persuade an audience (e.g., audio, video, written).

Grades Nine through Twelve:

- English: 1.5 Synthesize information from multiple sources and identify complexities and discrepancies in the information and the different perspectives found in each medium (e.g., almanacs, microfiche, news sources, in-depth field studies, speeches, journals, technical documents).

- Library: Use a variety of specialized search engines and databases to locate relevant information. Demonstrate proper procedures and good citizenship online.

Steps in Teaching Digital Citizenship

For learners to become digital citizens, they need to know the social impact of technology on them and by them, and assume responsibility for their actions.

\section{Awareness}

For learners to deal with digital information, they must first become aware of it. Life is full of information and informational needs: from stop signs to epistemologies, from finding a pencil sharpener to finding ways of dealing with illness. In educational settings, it is usually the teacher, such as the school librarian, who tries to call a learner's attention to information - or the 
need for information. Indeed, the existence of the need is, in itself, a piece of information that requires a sense of awareness for it to be acted upon. When school librarians can draw attention to a learner's own digital informational needs, be it as a positive experience or as a response out of fear of the consequences if they ignored the information (such as missing appointments or losing sight), then the information is more likely to be given the attention needed to become engaged with it.

\section{Engagement}

While learners are engaged with information, they are accessing it physically and intellectually. Before they can comprehend the information, they need to decode its "language", be it verbal, visual, or sound. Only then can they begin to understand the content in terms of associated concepts and societal consequences. If learners do not have the pre-requisite skills (linguistic, technical, experiential), they will not be able to connect; in these cases, school librarians need to scaffold the learning so students can bridge the intellectual gap. However, just because one understands digital information, does not mean that one will use it. The first consideration is usually the task at hand: what relationship does the information have with the identified task?

Assessment of evaluation seems straightforward: how efficiently and effectively does one evaluate information? What is the basis for their decision? How does one deal with new, contradictory information? Ultimately, the most valid assessment consists of examining the use of the information in deriving the final solution. In the digital world, learners may find it very hard to discern the verity of information because it can be modified so easily and with so much sophistication. School librarians need to teach explicit guidelines for evaluating the quality of digital information and its relevance. To check for learner understanding, and to engage them in active examination, debate, and self-reflection, school librarians can use a variety of technological tools: threaded discussion, online chat, blogs, wikis, and online conferencing.

Learners need to know both their digital rights as well as their digital responsibilities. When engaging with digital information from a legal or ethical standpoint, one of the most effective strategies is case studies. By examining the underlying conditions, the contributing factors, and the possible consequences, learners can form their own moral compass and make reasoned and ethical decisions. . As learners self-identify inappropriate digital behaviors and impacts, they become more aware of the problem. When they are involved in developing ways to solve the problem, they gain more ownership and control, feeling empowered to cope themselves as well as to help their peers.

\section{Manipulating Information}

The central question at this point is: what shall I do with the information? Digital information can be transformed into knowledge: through interpretation, organization, synthesis, reformatting, changing, relating, or combining it with other information. Digital information manipulation consists of four major processing skills: 1) extracting the information, 2) deciding how to represent the information, 3) determining the method of manipulating the information, and then 4) knowing how to do the manipulation itself (McCormick 1983). School librarians can couch these skills in authentic purposeful activities that enable them to become better digital consumers, such as comparison online shopping. 


\section{Application}

How does one act on the information? That is often the ultimate real-life goal, particularly as a digital citizen. Not only does it provide concrete evidence of learning, but it also demonstrates the value of interacting with digital information. It can improve oneself and one's surroundings. It offers a sense of empowerment that is important for an informed and engaged citizenry. Some student-empowering activities that enable learner to apply digital citizenship skills include:

- reviewing books, media, Internet sites

- creating products for the community: photos, artwork, videos, displays, posters, newsletters, web pages

- creating position papers and campaigns for communities and organizations

- capture community oral and visual history

- training and mentoring others in responsible technology use.

\section{Instructional Resources}

Throughout the instructional design process, school librarians need to determine which technologies will be used - and to what extent - to support digital citizenship. Such decisions need to be addressed in light of intellectual access for learning. At the very minimum, school librarians need to determine whether technology will be used as a tool to deliver instruction, as a learning aid, or as the outcome itself. Even the instructional focus, whether to emphasize a technology tool or educational task, requires careful consideration to make sure that learners have the prerequisite skills and knowledge in order to learn with technology - and consider its responsible and ethical use.

One model for providing K-12 digital citizenship instruction is a Digital Citizenship Toolkit, which offers a scalable solution to address student learning and achievement. Districtwide lessons (built with the district's template and informed by the school community) apply to all grades' standards in the core subject areas as well as P.E./health and the arts, to help students engage in meaningful content-rich activities. The lessons also address common core standards and library standards that cross curricular lines and also support digital/technological literacy. The fact that teacher librarians, classroom teachers and district leaders are involved throughout the development helps insure its appropriate content and use - as well as consistency across the district. School librarians provide accompanying bibliography of supporting digital resources enables faculty to draw upon other relevant resources to provide differentiated instruction as needed. Student-created videos model digital citizenship empowers students and provides peer support in responsible technological behavior. Face-to-face and video-based PD workshops (created according to the district's protocols) provide age-appropriate pedagogical methods of implementing the toolkit, and, again, facilitates consistent deployment across the district. Having these resources mounted on district or state services enables students and faculty to access not only the developed lessons but also web 2.0 tools so that the entire school community can learn anytime, anywhere. Parents too can access these lessons and so be partners at home to support their children's learning. 


\section{Future Research Directions}

Distance education provides a convenient way for school librarians to learn digital citizenship, and gain expertise in instructional design that can be applied in K-12 settings. In that regard, K-12 education is slowly embracing distance education itself; it can provide equity for hard-to-reach students, offer alternative digital citizenship instruction for students who are not successful in traditional settings (e.g., incarcerated, transitory, working). Furthermore, distance education itself has new delivery options.

Mobile devices have become commonplace tools used in teaching, learning, work and leisure, hence the word m-learning (Looi, et al., 2010). At the societal level, formal and informal learning merge as social network communities function as personal and personalisable spaces for online conversations and sharing of content (Clough, et al, 2008). The current wave of ubiquitous computing and social software tools enables an expanded repertoire of learnerteacher interaction, distributed collaboration, and communication, and their transformative effects on society, learning, and networking are becoming increasingly visible. Social networking sites support interaction and exchange of ideas between users they are also spaces for informal learning, and model the use of digital citizenship to contribute to society.

Furthermore, an abundance of resources are easily accessible via the Internet to teach digital citizenship. The Open Education movement allows personalization, customization and reuse of learning resources, and reduces the cost of materials and texts. The current movement is tackling perhaps one of the most crucial aspects for education: free and open access to educational resources being released under a commons license and thus the possibility to re-use those resources and to adapt them. The Open Education movement emphasises community building, participation and user generated content. Examples are The Open University (Open learn Labspace), Wikibooks and Wikiversity(Iiyoshi \& Kumar, 2008).

Social media software tools are being integrated into sound pedagogical strategies in order to add value to digital citizenship instruction, and facilitate authentic exchange and dialogue with and among students (Berg, Berquam \& Christoph, 2007). School librarians are starting to convince their sites that social networks and communities add value to the learning process, and ensure that social spaces and networks are used to support both formal and informal learning activities about digital citizenship (Jenkins, 2007).

It should be noted that digital citizenship has become even more relevant with the advent of globalization (Istance, Schuetze, \& Schuller, 2002). As education increasingly serves international learners, it has to address differences that arise from conflicting cultural norms about intellectual property, authority, and civic participation. A significant part of digital citizenship will need to be dedicated to negotiating these differences, largely in online venues.

The inclusion of social media and new delivery modes of curriculum is giving rise to Pedagogy 2.0, which clusters practices that advocacy learner choice and self-direction in engaging with relevant and flexible learning tasks (McLoughlin \& Lee, 2008). This framework melds well with the aims of digital citizenship. Some of its guidelines include:

- Content: micro units of content that can be chosen and shaped by teachers and learners

- Curriculum: negotiated content matter that can be interdisciplinary

- Communication: multiple formats, audiences, and directions

- Learning processes: situated, contextualized

- Resources: multiple formal and informal sources that are media-rich; highly granular learning objects, including learner-generated content 
- Learning tasks: authentic, personalized, learner-based.

Substantial research is needed to test all of these emerging practices. Digital citizenship provides a useful mapping for addressing these teaching and learning issues.

\section{Conclusion}

Digital citizenship is basically the safe, responsible, critical, and pro-active use of technology. The overarching goal is effective and responsible personal and social engagement with digital resources. School librarians are well positioned to teach these skills and habits, but they need training in this content matter as well as instructional design to conveying it.

Digital citizenship curriculum and standards have been developed, largely because of societal realities and demands. This content matter with its skills, knowledge and dispositions apply to K-20 education, keeping in mind developmental aspects. Librarians serve as experienced selectors of appropriate digital resources to support such instruction.

Distance education provides a good fit for both pre- and in-service school librarians to learn digital citizenship and instructional design. Not only does it offer a convenient and flexible learning environment, but it also enables school librarians to participate in aspects of digital citizenship in situo. Distance education is also being explored in K-12 settings, which requires the melding of digital citizenship in order to optimize learning and application. Furthermore, distance education can serve in formal and information capacities, which librarians as a whole should embrace.

Particularly as learning becomes global in audience, content, and delivery, digital citizenship will need to assume a foundational role, and informed librarians can spearhead these efforts.

\section{References}

American Association of School Librarians. (2007). Standards for the $21^{\text {st }}$ century learner. Chicago: American Library Association.

Berg, J., Berquam, L. \& Christoph, K. (2007). Social networking technologies: a "poke" for campus services. EDUCAUSE Review, 42(2), 32-44.

California State Department of Education. (2011). Adoption of preconditions of program standards for the teacher librarian services credential. Sacramento: California State Department of Education.

California State Department of Education. (2010). Model school library standards. Sacramento: California State Department of Education.

Clough, G., Jones, A., McAndrew, P., \& Scanlon, E. (2008). Informal Learning with PDAs and Smartphones. Journal of Computer Assisted Learning, 24, 359-371.

Federal Communications Commission. (2010). Broadband survey. Washington, DC: Federal Communications Commission.

Iiyoshi, T., \& Kumar, M. (2008). Opening up education. Cambridge, MA: MIT Press.

International Society for Technology in Education. (2008). Technology standards for teachers. Eugene, OR: International Society for Technology in Education. Retrieved September 15, 2011, 
from

http://www.iste.org/Content/NavigationMenu/NETS/ForTeachers/2008Standards/NETS T Stan dards Final.pdf

International Society for Technology in Education. (2007). technology standards for students. Eugene, OR: International Society for Technology in Education. Retrieved September 15, 2011, from

http://www.iste.org/Content/NavigationMenu/NETS/ForStudents/2007Standards/NETS for Stu dents 2007 Standards.pdf

Istance, D., Schuetze, H., \& Schuller, T. (2002). International perspectives on lifelong learning: From recurrent education to the knowledge society. New York: Open University Press.

Jenkins, H. (2007). Confronting the challenges of participatory culture: media education for the 21st Century. Chicago, IL: MacArthur Foundation.

Kennedy, S. (2010). The information today index. Information Today (May), 15-16.

Knowles, M., Swanson, R., \& Holton, E. (2011). The adult learner ( $7^{\text {th }}$ ed.). Burlington, MA: Butterworth-Heinemann.

Looi, C, Seow, P., Zhang, B., So, H., Chen, W., \&.Wong, L. (2010). Leveraging mobile technology for sustainable seamless learning: A research agenda." British Journal of Educational Technology, 41(2), 154-169.

Maloy, R., Verock-O'Loughlin, R., Edwards, S., \& Woolf, B. (2011). Transforming learning with new technologies. Boston: Pearson.

McCormick, M. (1983). Critical thinking and library instruction. RQ, 22(34).

McLoughlin, C. \& Lee, M.J.W. (2008). Future learning landscapes: transforming pedagogy through social software. Innovate: Journal of Online Education, 4(5). Retrieved September 15, 2011, from http://innovateonline.info/index.php?view=article\&id=539

National Governors Association. (2010). Common core state standards. Washington, DC: National Governors Association. 